\title{
ROUTINE PRODUCTION OF A TRITON BEAM FOR AN FN ACCELPRATOR
}

;

J.H. MoKay, P.G. Ashbaugh and J.T. Stark

Tandem Accelerator Laboratory, McMaster Univergity,

1280 Maia St. W., Hamilion, Ontario, Canada, LOS $4 \mathrm{~K} 1$

\author{
Abstract
}

The use of triton beams from tritiated titanium inserts in a sputter ion source has become a significant part of the Molaster Nuclear Physics programme. Tritium beams have been run on the McMaster University FN Tandem since 1978 on the basis of one scheduled running period per year accumulating a total of over 4000 hours of running time. Beams of up to one microamp are routinely put on target. Procedures for safe maintenance and operation of such a source have been developed, and techniques for handling up to $40 \mathrm{TBq}$ (about $1000 \mathrm{Ci}$ ) of tritium have been approved by the Atomic Energy Control Board.

\section{Introduction}

The use of a sputter ion source to generate a negative tritium ion beam for a tandem accelerator was suggested in 1973 by Middleton[1] and the technique was used at the University of Pennsylvania in 1977 for a run of about 700 hours duration[2]. Since then it has been used extensively at MoMaster University and recently at the Daresbury Nuclear Physics Laboratory[3].

In the sputter source, a negative ion beam is formed by the sputtering action of a 20 to $30 \mathrm{kV}$ caesium besm focused an an ingert containing a form of the desired ian species. It is possible to generate negative hydrogen ions from a titanium hydride ingert and similarly to generate nogative deuterium or tritium ions. While this is neither the easiest nor the mogt efficient method of generating negative hydrogen isotope beams, it does have the great advantage in the case of tritium, that no supply of gaseous tritium ig required in the source. This makes it feasible to run such $a$ beam in a normal laboratory if reasonable safety precautions are observed. The plans for producing a triton beam at Mokaster were described by Ashbaugh and Peng[4] in 1977. Tritium begms have been run in the laboratory on a regular bagis since 1978 with a beam on target of up to one microamp. Until this development, the only available tritium beams were at major laboratories such as Los Alamos using sources such ag the duoplasmatron, which require large inventories of gaseous tritium.

\section{Procedureg}

The McMaster Laboratory has eatablished procedures for regular operation and maintenance of such a source. In particular, we load our own sputter source inserts with tritium. These operational procedures have been approved by the Atomic Energy Control Board and are supervised by the University Health Physics staff. Tritium runs are scheduled for one period each year for about a month of running time.

A major convenience for the development of safe operating procedures was the location of a 50 metre high stack near the laboratory. A $75 \mathrm{~mm}$ diameter pipeline has been run through a service tunnel from the laboratory to the stack. All ion source and accelerator vacuum pumps $a s$ well as the tritium loading dry box, have been vented to this stack. A jlower at the base of the stack maintains a slight negative pressure in the line at all times. Assuming an accident that would dump all our tritium inventory into the stack, the dilution factor for a 50 metre stack is such that the emission of tritium into the air would still be more than two orders of magnitude below permissible limits.

We have found it possible to do repairs, such as replacement of ionizers, diffusion pumps, titanium sublimators etc., and to load and replace tritiated titanium sputter inserts without excessive exposures to personnel. The original source was based on a General Ionex Corp. model 830 sputter source, but, all source components are now built in our own shops. Severely contaminated parts are replaced, when cleaning would present a serious hazard. The original source body has been disposed of after use, due to build up of caesium on the high voltage insulators.

Safe routine operation is best achieved by careful planning of contamination control. Thorough cleaning before installation is part of this. Design of the vacuum system to contain any free tritium is a second major consideration. A $1 \mathrm{~cm}$ diameter tube $12 \mathrm{~cm}$ long at the entrance to the source box, forms a pumping restriction with a conductance of approximately $0.8 \mathrm{l} / \mathrm{s}$. The beam runs through an igolation tube in the source box which serves to reduce contamination. An Edwards Diffstak and a titanium sublimation pump are used on the source body to maintain a clean vacuum. The titanium pump bas a very high pumping speed for tritium and most of the gas is trapped there. A second titanium sublimation pump is mounted on the inflection magnet box.

\section{Tritium Loading}

The raost complex procedure involved in tritium overation, is the loading of tritium into the titanium inserts used in the source. The apparatus is contained in a glove box held at a slight negative pressure. The gaseous tritium is transferred from the shipping cylinder to a cylinder containing uranium powder where it is held in the uranium until it is heated. This is a standard method of storage of tritium. The titanium ingerts are mounted in $a$ pyrex tube where they are outgassed by R.F. induction heating. Tritium gas is introduced to the pyrex tube while the inserts gre held at about $800^{\circ} \mathrm{C}$. The tritium combines with the titanium in the form of a hydride. Up to $4 \mathrm{TBq}$ (about $100 \mathrm{Ci}$ ) of tritiun can be absorbed into each insert. The inserta are $4.5 \mathrm{~mm}$ in diameter by $3.2 \mathrm{~mm}$ long and weigh about $0.2 \mathrm{gm}$. The whole syster is constructed with metal seal valves and gaskets and pumped by a small ion pump. When the inserts are cooled, they are removed from the vacuum system and then taken from the dry box through an airlock. At this point, no tritium gas can be detected escaping from the titanium insert. The inserts are then pressed into aluminum holders (usualiy referred to as cones). This is done in $a$ fume hood. The installation of the insert holders into the source is a hazardous task due to the possibility of contamination from particulate matter in the source. For this, air masks and double rubber gloves are worn and tritium levels in the room air are constantly monitored. 


\section{Installation}

The tritium source is stored on a special stand when not in use, where its vacuum system is kept in operation at all times. Before mounting the tritium source, all other sources are removed from the ion source box or blanked off and the source box is cleared. The tritium source is then moved from its storage stand and connected to $a$ port of the source box. The tritium source is mounted on the exterior of the source box. Quick disconnect fittings are used for water and electrical supplies so that the source is under static vacuum for only a short time. The isolation tube is installed in the source box at this point. A sridded lens is contained in the isolation tube assernbly.

An extensive system of vacuum, waterflow and electrical interlocks protect the tritium source against all the normal operational problems. Any failure will cause the source to shut down, and the vacuum valves to close. In addition, the slight vacuum in the exhaust line to the stack muat be maintained, or the source will automatically be tripped.

\section{Operation}

Generally the source is run continuously during each period to avoid problems caused by shutdown and startup. This does not, however, seem to be great problem and we are not as strict about this rule as when we started. The key to long term reliability is to run the source quite conservatively. Startup must be given time and temperatures must be kept lower than normaI sputter source operating levels. A slow and careful shutdown ensures long ionizer lifetime. If the source is run in such a manner, decontamination and repair problems are much reduced. Licensing conditions, at present, require that we have regular operations ataff on duty 24 hours a day during Tritium runs. (During other muns, students and/or researchers are in charge for the off shifts.)

\section{Decontamination}

A rigorous cleanup at the end of the tritium run ensures control of contamingtion. The ion source box and the inflection magnet chamber are vented and evacuated (to the 50 metre stack) a number of times before being opened. Then the tritium solrece is moved back to its storage rack, the isolation tube and the gridded lens are remover, and the ion source box and inflection magnet chamber are scrubbed until the levels of tritium are reduced to safe levels. Removable components are cleaned in a fume hood dedicated for the purpose. The isolation tube and gridded lens are stored in that hood between runs. All varuum numps between the source and the accelerator are considered to be contaminated and are vented to the stack at all times. Maintenance work on these pumps must follow standard decontamination and monitoring procedures.
A number of detectors and procedures are used to monitor and control contamination. A Johnston Laboratories model $955 \mathrm{~B}$ triton detector is used to monitor tritium concentration in the air at all times. It is especially useful when opening the source for repairs or installation of cones. A Berthold LB $121 \mathrm{OB} / \mathrm{LB} 6255$ open window gas ionization detector is used to check for surface contanination. In addition the Health Physics group takes routine 'swipes throughout the building and regular urine tests check for personnel contamination. In seven years of running, the maximum recorded tritium exposure was equivalent to about $0.1 \mathrm{mSv}(10 \mathrm{mR})$. As the source ages, contamination levels have tended to rise and greater care is required while maintaining the source. The hazard due to tritium embedded in Faraday cups, apertures and slits has been shown by experience to be slight, but these items are radioactive due to years of bombardment particularly with intense beams of deuterons, so the additional hazard is covered by safety precautions already in place.

\section{Summary}

Since 1978, we have accurulated over 4000 hours of tritium running time in seven scheduled periods. The method of production of triton beams from a sputter source has been proven to be efficient and safe. We are in the nidst of an eighth tritium beam schedule as of this writing and expect to continue this aspect of our operation to serve the needs of the local research faculty and of visiting scientists from many other institutiona in North America and elsewhere.

$\begin{array}{cc}\text { TRITIUM RUN } & \text { SCHEDULES } \\ & \\ 1978 & 360 \text { HOURS } \\ 1979 & 830 \\ 1980 & 110 \\ 1981 & 1273 \\ 1982 & 95 \\ 1983 & 900 \\ 1984 & 495 \\ \text { TOTAL } & \frac{4063}{406} \text { hours }\end{array}$

\section{References}

[1] R. Middleton, in the Symposium of North-Eastern Accelerator Personnel, 1983, ps 6?.

[2] R. Middleton, C.T. Adams and R.V. Kollarits, "Acceleration of Tritium in an FN Tandem Accelerator", Nucl. Instr. and Meth., 151 (1978) $41-45$.

[3] T.R. Charlesworth, private communication

[4] P.G. Ashbaugh and Y. Peng, "A Proposal to Produce a Triton Beam Jsing a Caesium Sputter Source", Revue de Phyaique Appliquee, vol 12, Oct $1977, \overline{1449-1452}$ 